\title{
Efficacy and safety of nitrous oxide in alleviating pain and anxiety during painful procedures
}

\author{
S A Kanagasundaram, L J Lane, B P Cavalletto, J P Keneally, M G Cooper
}

\begin{abstract}
Aims-To evaluate the efficacy and safety of nitrous oxide for children undergoing painful procedures.

Methods-Ninety children requiring repeated painful procedures (lumbar puncture, bone marrow aspirate, venous cannulation, or dressing changes) were given nitrous oxide at a variable concentration of $50-70 \%$. Procedure related distress was evaluated using the Observational Scale of Behavioral Distress-Revised (OSBD-R). OSBD-R scores were obtained for each of the following phases of the procedure: phase $1 \mathrm{a}$, waiting period; phase $\mathrm{lb}$, during induction with nitrous oxide; phase 2 , during positioning and cleaning of the skin; phase 3 , during the painful procedure; and phase 4 , immediately following the procedure and withdrawal of nitrous oxide. Side effects were monitored and recorded by a second observer.
\end{abstract}

Results-OSBD scores reached a maximum during the induction phase with lower scores during subsequent phases. Children over the age of 6 showed a lower level of distress during nitrous oxide administration and the painful procedure. Eighty six per cent of patients had no side effects. The incidence of vomiting, excitement, and dysphoria was $7.8 \%, 4.4 \%$, and $2 \%$ respectively. Eight patients developed oxygen desaturation $\left(\mathrm{SaO}_{2}<95 \%\right)$, but none developed hypoxia, airway obstruction, or aspiration. Ninety three per cent of patients fulfilled the criteria for conscious sedation, and $65 \%$ had no recollection of the procedure. Mean recovery time was three minutes.

Conclusions-Inhalation of nitrous oxide is effective in alleviating distress during painful procedures, with minimal side effects and short recovery time. (Arch Dis Child 2001;84:492-495)

Keywords: nitrous oxide; pain; anxiety; painful procedure

Procedures such as venous cannulation, bone marrow aspiration, lumbar puncture, and dressing changes are painful and anxiety provoking in the paediatric population. Administration of sedative, hypnotic, amnesic, and analgesic agents, either alone or in combination have been used to diminish pain and anxiety during these procedures, with varying success. ${ }^{1}$

Nitrous oxide is a potent inhalational agent that can provide analgesia, some sedation, and reduce anxiety. The effectiveness of $50 \%$ and
$70 \%$ nitrous oxide in reducing the pain and anxiety associated with venous cannulation has been described. ${ }^{2}$ It has also been reported that nitrous oxide is a well tolerated and effective analgesic in children for outpatient procedures. $^{3-5}$ These reports compared the efficacy of nitrous oxide to placebo or an alternative pharmacological agent, and confirmed a significant reduction in pain scores when nitrous oxide was administered for painful procedures. However, they fail to describe the effect of nitrous oxide analgesia on children's emotional and behavioural response. Apart from efficacy, the adverse effects, side effects, and recovery characteristics of this agent must be considered in evaluating its success for painful procedures.

In a prospective study, we investigated the effects of nitrous oxide on children's behavioural responses to painful procedures. We planned to identify variables that related to high distress scores. The incidence of adverse effects and recovery characteristics was also evaluated.

\section{Patients and methods}

This study was approved by the institutional ethics committee. Following informed consent, patients were prospectively recruited into the study if it was planned that they undergo venous cannulation, bone marrow aspiration, lumbar puncture, or dressing change. Patients were recruited with medical, surgical, and oncological conditions. Ninety patients were enrolled in the study. Each patient was enrolled only once and 34 patients had more than one procedure performed. No premedication was used. Exclusion criteria included impaired level of consciousness, undrained pneumothorax, recent middle ear surgery, and a difficult airway. Patients were fasted from solids for four hours and clear fluids for two hours prior to the procedure. The apparatus used to administer nitrous oxide at a variable concentration consisted of the Quantiflex Mark II Relative Analgesia machine (Cyprane, Keighley, Yorkshire, UK) and a Bain circuit. The relative analgesia machine is a constant flow device and has a failsafe of a minimum of $30 \%$ oxygen at all times. The procedures were carried out in ward treatment rooms equipped with scavenging and monitoring facilities.

Nitrous oxide was administered by one of the nursing investigators who had been trained in the use of nitrous oxide by a member of the anaesthetic department. Nitrous oxide was administered at a variable concentration of $50-70 \%$ to achieve a level of consciousness that retained the patient's ability to maintain verbal 
Table 1 Sedation scoring system

\begin{tabular}{ll}
\hline Sedation score & Response \\
\hline 0 & Unrousable \\
1 & Asleep, rousable \\
2 & Drowsy \\
3 & Awake \\
\hline
\end{tabular}

Table 2 Mean rank of scores by age group

\begin{tabular}{llllllll}
\hline & $1 a$ & $1 b$ & 2 & $3 a$ & $3 b$ & 4 & Total \\
\hline $1-5$ & 49.3 & 59.9 & 46.6 & 57.4 & 44.6 & 60.8 & 61.2 \\
$6-10$ & 43.7 & 42.4 & 45.1 & 42.9 & 43.7 & 37.3 & 40.5 \\
$11+$ & 41.5 & 30.2 & 42.9 & 32.7 & 47.4 & 36.4 & 31.4 \\
$\mathrm{p}$ value & 0.412 & 0.000 & 0.780 & 0.001 & 0.661 & 0.000 & 0.000 \\
\hline $\mathrm{p}<0.05$. & & & & & &
\end{tabular}

or tactile communication with the administrator. Children over the age of 3 received preprocedural teaching in correct use of the mask. Cognitive therapy that included imagery, distraction, and positive incentive was an integral part of the procedure and was provided by the administrator. Parents were encouraged to be present during the procedure. Nitrous oxide was administered for at least three minutes prior to the painful procedure and continuously throughout it. At the end of the procedure, the patient was allowed to breathe $100 \%$ oxygen for two to three minutes. Monitoring included pulse oximetry and end tidal gas analysis to measure the concentration of expired nitrous oxide and oxygen.

Procedure related distress was measured by trained observers using the scale of Observational Scale of Behavioral Distress-Revised (OSBD-R), an observation instrument with established reliability and validity that is used to evaluate distress. ${ }^{6}$ The presence or absence of eight operationally defined behaviours which indicate pain and anxiety (cry, scream, physical restraint, verbal resistance, seeks emotional support, information seeking, verbal pain, flail) is recorded by trained observers at 15 second intervals throughout the procedure and weighted according to the severity of distress. The weighted scores are summed during each 15 second interval and then divided by the number of intervals to obtain a mean score for each phase.

OSBD scores were obtained for each of the following phases of the procedures:

- Phase $1 \mathrm{a}$-waiting period

- Phase $1 \mathrm{~b}$-during induction with nitrous oxide

- Phase 2-during positioning and skin cleaning

- Phase 3a-during the painful procedure

- Phase 3b-during the second procedure (where performed)

- Phase 4-immediately following the procedure and withdrawal of nitrous oxide.

Table 3 Mean rank of scores by procedure

\begin{tabular}{llllllll}
\hline Phase & $1 a$ & $1 b$ & 2 & $3 a$ & $3 b$ & 4 & Total \\
\hline Lumbar puncture & 44.5 & 41.9 & 44.2 & 43.6 & 45.6 & 41.2 & 41.2 \\
Venous cannulation & 38.9 & 48.9 & 40.4 & 35.9 & 42.1 & 47.7 & 42.8 \\
Dressing & 60.0 & 59.3 & 42.0 & 60.0 & 39.0 & 62.3 & 59.8 \\
Bone marrow aspiration & 44.9 & 38.6 & 51.3 & 44.4 & 57.3 & 37.4 & 44.2 \\
p value & 0.205 & 0.193 & 0.213 & 0.099 & 0.024 & 0.021 & 0.186
\end{tabular}

$\mathrm{p}<0.05$.
Prior to the study, two observers were trained in the use of OSBD-R until they obtained a minimum of $90 \%$ interobserver agreement.

A third observer recorded evidence of specified adverse effects: vomiting, excitement, dysphoria, and desaturation. Definition of desaturation was $\mathrm{SaO}_{2}<95 \%$. This was chosen as the patients were receiving an $\mathrm{FiO}_{2}$ of $30-50 \%$. Excitement was defined as uncontrolled laughing or hysteria and dysphoria was described as unpleasant dreams. The level of sedation was rated on a scale $0-3$ (table 1 ) by noting the response to touch and voice during phase 2 and phase 3 . The length of time for recovery was recorded as the time taken from phase 4 to sitting up on command. Children over the age of 3 were questioned for recollection of the procedure.

\section{STATISTICS}

Patients' ages were categorised into three groups: $1-5$ years, $5-10$ years, $>11$ years. The Kruskal-Wallis test was then used to examine the distribution of scores between the three categories. Distribution of scores with regard to previous experience with nitrous oxide for painful procedures was categorised as none, $1-5$, or $6-10$, and compared using the Kruskal-Wallis test. The primary procedure was recorded as lumbar puncture, cannulation, bone marrow aspiration, or dressing changes. The distribution of OSBD scores among these categories was compared using the KruskalWallis test. These non-parametric tests are equivalent to $t$ and $\mathrm{F}$ tests applied to the ranks of the data. Tables 2, 3 and 4 show the mean ranks. Higher means indicate a greater level of distress. Significance level was set at $\mathrm{p}<0.05$.

\section{Results}

Scores were obtained using the OSBD-R for 90 patients administered continuous nitrous oxide while undergoing painful procedures. Table 5 shows patient demographics and procedure characteristics. The OSBD-R scores were obtained for each of the six phases. The higher scores indicated a greater level of distress. Table 6 presents the median scores along with the lower and upper quartiles.

Significant differences in the mean ranks between the three age categories were seen for the total OSBD score $(\mathrm{p}=0.000)$ and scores

Table 4 Mean rank of scores by number of previous experiences with nitrous oxide

\begin{tabular}{llllllll}
\hline Phase & $1 a$ & $1 b$ & 2 & $3 a$ & $3 b$ & 4 & Total \\
\hline 0 & 47.8 & 50.9 & 44.7 & 47.7 & 46.1 & 47.6 & 50.0 \\
$1-5$ & 43.7 & 41.6 & 44.5 & 41.5 & 42.7 & 43.4 & 40.5 \\
$6-10$ & 43.2 & 39.5 & 47.9 & 45.3 & 47.2 & 43.8 & 42.3 \\
p value & 0.652 & 0.136 & 0.777 & 0.627 & 0.603 & 0.695 & 0.288
\end{tabular}

$\mathrm{p}<0.05$.

Table 5 Patient demographics and procedure characteristics

\begin{tabular}{lllll}
\hline $\begin{array}{l}\text { Age (y) } \\
\text { Mean (SD) }\end{array}$ & $\begin{array}{l}\text { Sex } \\
\text { F:M }\end{array}$ & Procedure & $\begin{array}{l}\text { Number } \\
(n=90)\end{array}$ & $\begin{array}{l}\% \text { of } \\
\text { children }\end{array}$ \\
\hline $7.32(4.02)$ & $42: 48$ & Lumbar puncture & 45 & 50 \\
& & Bone marrow aspiration & 14 & 15.6 \\
& & Venous cannulation & 14 & 15.6 \\
& & Dressing changes & 17 & 18.8 \\
\hline
\end{tabular}


Table 6 OSBD score for each phase, median (range)

\begin{tabular}{llll}
\hline & Lower & Median & Upper \\
\hline Phase 1a & 0 & 0 & 0.34 \\
Phase 1b & 0 & 0.41 & 2.02 \\
Phase 2 & 0 & 0 & 0 \\
Phase 3a & 0 & 0.31 & 1.5 \\
Phase 3b & 0 & 0 & 0 \\
Phase 4 & 0 & 0 & 0.71 \\
\hline
\end{tabular}

Table 7 Frequency of previous experience with nitrous oxide

\begin{tabular}{ll}
\hline Number of previous exposures & Number of patients $(n=90)$ \\
\hline 0 & 42 \\
$1-5$ & 24 \\
$6-10$ & 24 \\
\hline
\end{tabular}

Table 8 Incidence of adverse effects

\begin{tabular}{ll}
\hline Adverse effects & Incidence $(\%)(n=90)$ \\
\hline Vomiting & 7.8 \\
Excitement & 4.4 \\
Dysphoria & 2.0 \\
Desaturation & 8.9 \\
\hline
\end{tabular}

Table 9 Level of sedation

\begin{tabular}{ll}
\hline Sedation score & Incidence $(\%)(n=90)$ \\
\hline 0 (unrousable) & 0 \\
1 (asleep, rousable) & 1.1 \\
2 (drowsy) & 5.6 \\
3 (awake) & 93.3 \\
\hline
\end{tabular}

Table 10 Recovery parameters

\begin{tabular}{ll}
\hline Amnesia & $65 \%(\mathrm{n}=66)$ \\
Mean recovery time (SD) & $3.08(1.37)$ minutes \\
\hline
\end{tabular}

for phase $1 b \quad(p=0.000)$, phase $3 a$ $(p=0.001)$, and phase $4(p=0.000)$. In all cases, a gradient of higher mean rank for the younger children through to lower mean rank for the older children was observed.

There were significant differences between the various procedures in phases 3 and 4 . Dressing changes scored highly in phases $3 \mathrm{a}$ and 4 . Table 7 shows the frequency of previous experience with nitrous oxide for procedures. No significant difference between scores was found with regard to frequency of previous nitrous administration for painful procedures. Tables 8, 9, and 10 show incidence of adverse effects, level of sedation, and recovery parameters respectively.

\section{Discussion}

Procedures such as venous cannulation, bone marrow aspiration, lumbar puncture, and dressing changes are painful and provoke anxiety in the paediatric population. Pharmacological agents have been used alone and in various combinations with varying success. ${ }^{1}$ The properties of an ideal agent include analgesia, anxiolysis, amnesia, and minimal side effects. The agent should have a rapid and predictable onset and characteristics that allow early recovery. A painless route of administration is also important. Venous cannulation is in itself painful and it is better if this can be avoided.

Inhaled nitrous oxide provides pain relief, sedation, and alleviation of anxiety. These benefits were shown in paediatric dentistry, ${ }^{7}$ and more recently in relieving pain and anxiety associated with procedures in children in the emergency department. ${ }^{3-5}$

EFFICACY

Although the OSBD-R scale has been used to compare the effects of intervention in two different groups of patients, ${ }^{8}$ we used the scale to investigate the effect of intervention within a single group of patients. The numerical score during each phase describes the level of distress experienced by the child. Our scores revealed a significant elevation in the level of distress during the administration of nitrous oxide and a reduction during the subsequent phases of procedures, including the painful phase (table 6 ). This observation of increased score during phase $\mathrm{lb}$ could be caused by numerous factors, including the application of the mask and nitrous oxide inhalation. Other potential causes are anticipation of the procedure and parental separation. The subsequent reduction in distress score during phases 2,3 , and 4 shows that continuous nitrous oxide administration decreases the level of distress to a minimal level. Studies which have evaluated the efficacy of ketamine and midazolam for painful procedures by using the OSBD-R scoring system show an elevation in scores during the painful phase of the procedure (phase 3). ${ }^{8-10}$

The efficacy of nitrous oxide is attributed to its analgesic and sedative properties, which produce a sense of euphoria and detached attitude towards pain and surroundings. However, this effect can be variable and nitrous oxide may fail to produce an analgesic effect in some patients. ${ }^{11}$ Reasons for failure include poor technique of administration and the mask actually increasing the child's level of anxiety.

Previous studies of the use of nitrous oxide for venous cannulation, ${ }^{2}$ laceration repair, and orthopaedic manipulation $^{3-5}$ in the paediatric population have not discussed specific indications for or limitations of the use of the agent. However, this study was able to identify groups that consistently showed low level of distress during the administration of nitrous oxide and the painful procedure. Patients in the age groups $>11$ years and 6-10 years had lower scores during phase $1 \mathrm{~b}$ (application of face mask), phase 3 (the painful procedure), and phase 4 . This was also reflected in the total score.

Jay et al reported that age was the strongest predictor of children's distress during bone marrow aspirations. ${ }^{12}$ Katz et al showed that young children tend to emit a greater variety of anxious behaviours over a longer period of time than older children do. ${ }^{13}$ Application of this information to our findings suggests that administration of nitrous oxide for painful procedures in very young children may not be as effective compared with older children. Our clinical impression is that older children have a better understanding of the correct technique of breathing into a facemask and also benefit from the cognitive therapy that accompanies this technique.

In our institution, imagery, distraction, and positive incentive are strategies that have 
become an integral part of the technique of nitrous oxide administration for procedural pain. Jay et al reported equivocal results with respect to distress when cognitive therapy was compared with general anaesthesia for painful medical procedures in children. ${ }^{14}$ The suggestion that combination of cognitive behavioural intervention with general anaesthesia may diminish distress than either treatment alone was also raised. ${ }^{15}$ Ninety three per cent of the patients in this study were able to communicate with the administrator during inhalation of nitrous oxide and able to participate in imagery and positive incentive while benefiting from the euphoric and anxiety alleviating properties of nitrous oxide. We consider that cognitive therapy should be an integral part of the technique of nitrous oxide administration for alleviation of distress in children. With respect to procedures, patients undergoing dressing changes scored higher than those undergoing other procedures. The score remained high during the recovery phase. The higher score may be related to the longer length of the procedure and persisting pain.

The most favourable characteristic of nitrous oxide in this study was the effect on recovery parameters, namely short recovery time and amnesic effect. This characteristic is particularly beneficial to children with an oncological diagnosis who require repeated painful procedures. The amnesic effect allows repeated procedures to be conducted with minimal distress and the favourable recovery characteristics allow these procedures to be conducted on a day stay basis with minimal disruption to patient and family.

SAFETY

The safety of the pharmacological agent of choice for painful procedures in ambulatory patients relies on minimal adverse effects and favourable recovery characteristics. The safety of nitrous oxide for dental surgery in paediatric patients was reported by Roberts and colleagures. ${ }^{7} \quad$ Griffin et al also described a technique for safe utilisation of nitrous oxideoxygen sedation in 3000 children undergoing minor surgical procedures. ${ }^{16}$ Some clinicians discourage the use of nitrous oxide for alleviating pain and distress during painful procedures for fear of inappropriate use that may lead to hypoxia, loss of consciousness, and gastric aspiration.

The definition of desaturation in this study $\left(\mathrm{SaO}_{2}<95 \%\right)$ was higher than in other studies which have used $\mathrm{SaO}_{2}<92 \%$ as their definition. Although eight patients in our study developed episodes of relative desaturation $\left(\mathrm{SaO}_{2}<95 \%\right)$, none were observed to develop airway obstruction or hypoxia. All the patients in our study were unpremedicated and our results revealed that $93 \%$ of the patients were in communication with the administrator during the procedure and thus fulfilled the criteria of conscious sedation. ${ }^{17}$ The remaining patients were drowsy but rousable. The reported incidence of nausea and vomiting during nitrous oxide administration is $14-19 \%{ }^{18}$ and can place patients at risk if they are unable to protect their airway. In this study, the incidence of vomiting was low $(7.8 \%)$ compared to other studies and there was no aspiration. While this study indicates that vomiting and aspiration may not be a problem, as was previously thought, it should be noted that more than $90 \%$ of our patients fulfilled the criteria of conscious sedation.

\section{CONCLUSION}

In summary, this study shows that administration of nitrous oxide/oxygen for painful procedures in children maintains low distress scores during the painful phase. Its most appropriate application is to children over the age of 6 and for short procedures. The low incidence of adverse effects and short recovery time in unpremedicated children allow safe administration by non-anaesthetists outside the operating theatre.

This study was funded by BOC Gases Australia Ltd. The authors acknowledge W Xuan and M Griffin for their assistance with the statistical analysis.

1 Anderson CTM, Zeltzer LK, Fanurik D. Procedural pain. In: Schechter NL, Berde CB, Yaster M, eds. Pain in infants, children and adolescents. Baltimore: Williams \& Wilkins, children and ado

2 Henderson JM, Spence DG, Komocar LM. Administration of nitrous oxide to pediatric patients to provide analgesia for venous cannulation. Anesthesiology 1990;72:269-71.

3 Gamis AS, Knapp JF, Glenski JA. Nitrous oxide analgesia in a pediatric emergency department. Ann Emerg Med 1989;18:177-80.

4 Evans JK, Buckley SL, Alexander A. Analgesia for the reduction of fractures in children: a comparison of nitrous oxide with intramuscular sedation. $\mathcal{F}$ Pediatr Orthop 1995;15:73-7.

5 Hennrikus AT, Shin AY, Klingelberger CF. Selfadministered nitrous oxide and hematoma block for analgesia in the outpatient reduction of fractures in children. F Bone foint Surg 1995;77:335-9.

6 Elliott CH, Jay SM, Woody P. A behavioral observation scale for measuring children's distress during medical procedures. F Pediatr Psychol 1987;12:543-51.

7 Roberts GJ, Gibson A, Porter J, Zoysa S. Relative analgesia: Roberts GJ, Gibson A, Porter J, Zoysa S. Relative analgesia:
an evaluation of the efficacy and safety. Br Dent $\mathscr{f}$ an evaluation of

8 Marx CM, Stein J, Tyler MK. Ketamine-midazolam versus meperidine-midazolam for painful procedures in pediatric oncology patients. F Clin Oncol 1997;15:94-102.

9 Friedman AG, Mulhern RK. Midazolam premedication for pediatric bone marrow aspiration and lumbar puncture. Med Pediatr Oncol 1991;19:499-504.

10 Tobias JD, Phipps S. Oral ketamine premedication to alleviate the distress of invasive procedures in pediatric oncology patients. Pediatrics 1992;90:537-41.

11 Hennrikus W, Simpson RB, Klingelberg C. Selfadministered nitrous oxide analgesia for pediatric fracture reductions. F Pediatr Orthop 1994;14:538-42.

12 Jay SM, Ozolins M, Elliott CH. Assessment of children's distress during painful medical procedures. Health Psychol 1983;2:133-47.

13 Katz ER, Kellerman J, Siegal E. Behavioral distress in children with cancer undergoing medical procedures: developdren with cancer undergoing medical procedures: develop-
mental considerations. $\mathcal{f}$ Consult Clin Psychol 1980;48:35665 .

14 Jay SM, Elliott CH, Fitzgibbons I. A comparative study of cognitive behavior therapy versus general anaesthesia for painful medical procedures in children. Pain 1995;62:3-9. 15 Berde C. Pediatric oncology procedures: editorial. Pain 1995;62:1-2.

16 Griffin G, Campbell V, Jones R. Nitrous oxide-oxygen sedation for minor surgery. Experience in a pediatric setting. fAMA 1981;245:2411-30.

17 American Academy of Pediatrics. Guidelines for monitoring and management of pediatric patients during and after sedation for diagnostic and therapeutic procedures. Pediatrics 1992;89:1110-15.

18 Houck WR, Ripa LW. Vomiting frequency in children administered nitrous oxide/oxygen in analgesic doses. $\mathcal{f}$ Dent Child 1971;38:404-7. 